\title{
Study of Task Scheduling in Cloud Computing Environment Using Soft Computing Algorithms
}

\author{
Saurabh Bilgaiyan, Santwana Sagnika, Samaresh Mishra, Madhabananda Das \\ KIIT University, Bhubaneswar, 751024, India \\ Email: \{ saurabhbilgaiyan01, santu.hmm, samaresh2, mndas12\}@gmail.com
}

\begin{abstract}
Cloud computing is a popular computing concept that performs processing of huge volume of data using highly accessible geographically distributed resources that can be accessed by users on the basis of Pay as per Use policy. Requirements of different users may change so the amount of processing involved in such paradigm also changes. Sometimes they need huge data processing. Such highly volumetric processing results in higher computing time and cost which is not a desirable part of a good computing model. So there must be some intelligent distribution of user's work on the available resources which will result in an optimized computing environment. This paper gives a comprehensive survey on such problems and provide a detailed analysis of some best scheduling techniques from the domain of soft computing with their performance in cloud computing.
\end{abstract}

Index Terms-Cloud computing, Quality of services (QoS), virtualization, scheduling, swarm based algorithms, optimization.

\section{INTRODUCTION}

Cloud computing is an emerging field of computing where a set of resources (i.e. hardware and software resources) are accessible as a service to the user but not as a product. The best part about this computing paradigm is, user need not to be worried about the physical resource locations and number of available instances of any resources [1]. Cloud computing is efficient because it provide multilevel abstraction and a series of virtualization layers by which it becomes a more resourceful network-based resource computing. Broadly, we can say that there are three types of services of cloud computing: (1) PaaS (platform as a service) (2) SaaS (software as a service), and (3) IaaS(infrastructure as a service) [2]. There are some good cloud offerings for such type of services i.e. Google, Amazon web services, GoGrid, etc.

Scheduling in the cloud environment is an NPcomplete problem. With the increases number of user's size of associated computing, sometime the tasks to be scheduled are proportionally increases, and the task scheduling existing strategies cannot fulfil its requirements. For these reason better algorithms for task scheduling is needed to reduce computation time and the cost associated with that computing. An efficient task scheduling algorithm directly affects the system performance [4].

Cloud computing has added the extra level of virtualization in the whole task allocation business which comes with the advantage of being easily scalable, but also has the downside of requiring an additional step in the scheduling. Whereas in grids users where simply required to find a subset of resources for their applications, in clouds they now have to find the resources, than find a way to allocate some VMs on them and finally schedule the tasks on the VMs.

There are different optimization algorithms used to solve these kinds of scheduling problems. Various algorithms are being proposed by researchers to allocate and schedule the resources in the cloud environment. This paper provide a study of different soft computing techniques that perform scheduling of tasks to resources, such as ant colony optimization, genetic algorithm, simulated annealing, particle swarm, and bee colony optimization, etc. Various modified scheduling algorithms like Improved Genetic Algorithm, Modified Multi-objective Particle Swarm Optimization have also been analyzed [5].

\section{RELATED WORK}

In cloud computing QoS (Quality of service) is an important issue. For an efficient cloud system QoS must be improved, for this waiting time must be reduced and tasks should be scheduled properly. There are various optimization algorithms to solve the tasks allocation and scheduling related problems. Here different soft computing techniques, genetic algorithm, particle swarm optimization, ant colony optimization, and bee colony optimization algorithm, etc are used to schedule tasks to resources. [5].

Savitha. P et al. (2013) [6] proposed a genetic algorithm (GA) for task scheduling in cloud computing environment. This proposed algorithm is well tested and results are compared with the existing genetic algorithm based workflow scheduling techniques. The results of proposed GA outperforms the existing methods.

Sourav banerjee et al. (2012) [7] has proposed Genetic algorithm (GA) to schedule the task for cloud service provider. This heuristic search method minimizes the waiting time of the overall computing system. In the proposed technique users send requests to the service provider who stores them in a queue, and then GA select the best job from that queue. In this way the effectiveness 
of GA minimizes the waiting time. GA based scheduling techniques are used to search optimize solution from a set of probable solution. This technique increases the system's throughput.

Pardeep Kumar et al. (2012) [8] have improved genetic algorithm on self-regulating task scheduling. Scheduling algorithm like minimum-minimum, maximum-minimum, particle swarm optimization and genetic algorithm, are used for resource utilization. The authors combined three scheduling techniques such as minimum-minimum, maximum-minimum and genetic algorithm. Performance of improved genetic algorithm is much better than standard genetic algorithm. It minimizes the makespan and properly utilizes the resource.

Lizheng Guo et al. (2012) [9] proposed a Particle swarm optimization techniques for multi objective task assignment in cloud computing environment. The proposed technique optimizes the time as well as cost for all tasks. This technique also includes time of processing, transferring, transfer and process cost.

Suraj Pandey et al. (2010) [10] proposed heuristic based particle swarm optimization for task scheduling to optimize the cost associated with computation and communication. PSO can properly balance the workflow and saves the cost as compared to existing technique(best resource selection).

Sheng-Jun Xue et al. (2012) [11] proposed a hybrid particle swarm algorithm for workflow scheduling in cloud environment. This newly proposed algorithm is named as GHPSO, a QoS based hybrid PSO technique. In GHPSO PSO is embedded with some part of Genetic Algorithm like crossover and mutation and hill climbing approach. So the performance of this new methodology is better than the standard PSO. It minimizes the execution time and cost.

C.W. Chiang et al. (2006) [12] has proposed task scheduling and matching using ant colony optimization. Here one algorithm is proposed named ACO-TMS that reduces the scheduling time and always help to search a satisfactory scheduling result by integrating local search procedure. The proposed technique is compared with some existing approach like GA and DPS heuristic. The new technique gives better result and minimizes the time as compared to the existing methodologies.

Linan Zhu et al. (2012) [13] proposed Ant colony optimization techniques to overcome the problem related to scheduling of resource. Here basic ant colony optimization is used to analyze and design the scheduling of resources in cloud. Cloudsim simulation tool is used to balance and distribute the load of nodes for better performance.

Hui Liu et al (2011) [14] has proposed QoS requirement related to service flow schedule problem using ant colony optimization technique. Here a scheduling model of service flow is proposed and ACO optimization method is implemented over this with the requirement of QoS. The four QoS properties are the objective of this model i.e. cost, security, reliability and response time. Result of the experiment shows that the model is more efficient than the standard one.

Dhinesh Babu L.D et al. (2013)[15] proposed honey bee behaviour based task load balancing. In this paper one honey bee behaviour based algorithm is proposed named HBB-LB to manage the task priority and minimize the time. The proposed methodology is more efficient and gives less execution time, waiting time as compared to existing load balancing and scheduling approaches.

Sung-Soo Kim et al. (2013) [16] has proposed binary artificial bee colony algorithm for job scheduling problem in grid environment. Here proposed BABC (binary artificial bee colony) technique minimizes the makespan and solves job scheduling problem more efficiently than some alternative approaches like PSO, GA, simulated annealing.

Saurabh Bilgaiyan et al. (2014) [17] proposed a new cat swarm optimization algorithm (CSO) for workflow scheduling in cloud environment. The proposed a CSO method outperforms the existing PSO algorithm in terms of speed of convergence in terms of iterations. Also it provide a better load distribution over resources.

\section{SOFT COMPUTING APPROACHES}

Task scheduling has become one of the major key areas for research. There are a number of soft computing techniques available for solving complex problems. This paper basically deals with soft computing techniques to solve various problems in task scheduling in cloud computing environment. The authors provide a study of different algorithms such as genetic algorithm, particle swarm optimization, ant colony optimization, artificial bee colony for efficient scheduling of tasks to resources.

\section{A. Genetic Algorithm}

Genetic algorithms are basically inspired from theory given by Darwin's about evolution. The solution to the problem is given by genetic algorithm starts with a solution set (i.e. chromosomes) called the population. Solutions from a particular population are taken into account and used to generate a new population [18]. This is enthused, that the new population will be improved from the old one. Solutions are selected to form new ones (offspring) which are selected according to their fitness.

Genetic algorithm follows meta-heuristic approach. This heuristic regularly used to produce useful solution to optimization and search problems. Genetic algorithms belong to class of evolutionary algorithms, which generates solutions to optimize problems using technique inspired by natural evolution, such as inheritance, mutation [19]. Basic steps of genetic algorithm are represented by Fig. 1. 


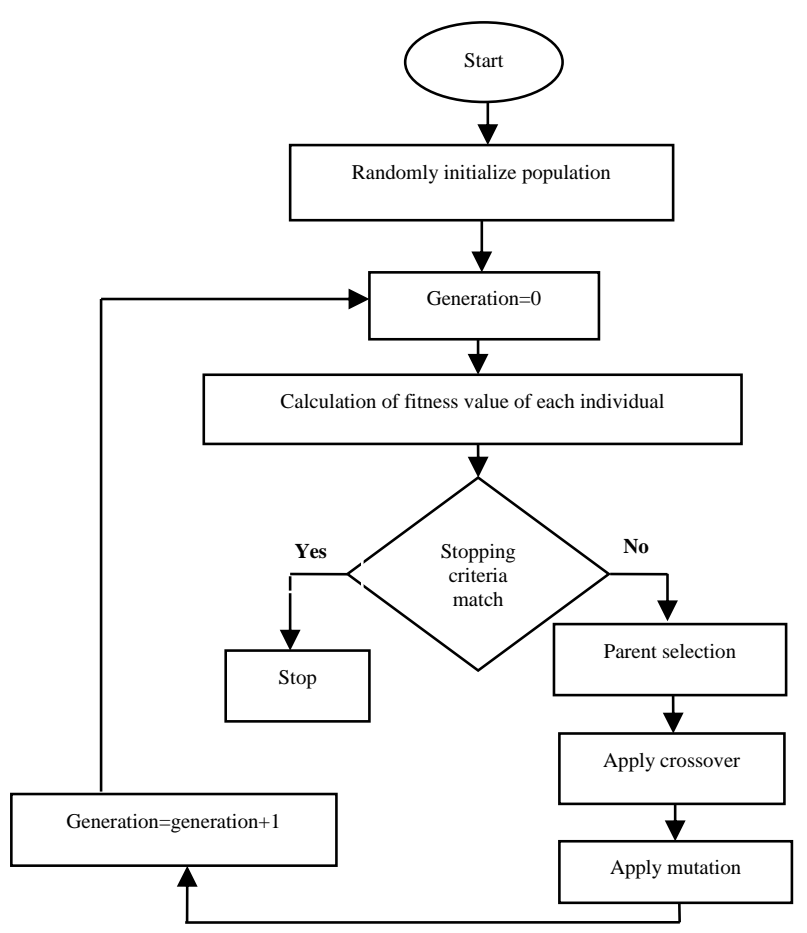

Fig. 1. Flow chart for genetic algorithm

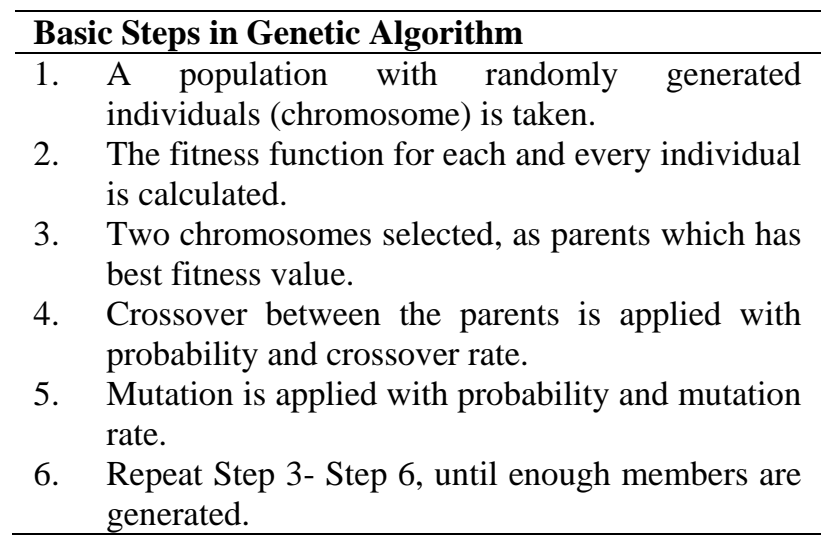

Step 3 is repeated, till stopping criteria is met.

\section{1) Application Areas for genetic algorithm}

Genetic algorithm is an interdisciplinary field which develops methodology for retrieving, storing, organizing, analyzing data. It is also used in optimization of operational and structural design of factories, buildings and machines. Genetic Algorithms are inspired by the mechanisms of progress in the field of biological science. Genetic algorithm primarily depends on inherent parallelism, using selection in secondary roles and mutation in design solution. Genetic algorithm applications analyze the natural designs and combines designs to create entirely new things.

\section{2) Advantages of genetic algorithm in Task Scheduling}

Genetic algorithm is useful in solving variety of optimization problems. It is basically applied to dynamic scheduling problems with multiple tasks. These Task must be non-identical, autonomous numerous task. They must be distributed in shared multiprocessor memory system. Structural Genetic Algorithm provides the option of solving the solution structure solution parameter problems with accuracy.

\section{B. Particle Swarm Optimization}

Recently PSO is developing as a well-known heuristic approach, which is applied to many multifaceted and large problems; it is used in solving extraction of knowledge in data mining, solving scheduling of task problem, power systems, etc. PSO generally follow the arbitrary searching in solution space by means of a large population, depending upon the domain. Basic steps of particle swarm optimization is represented by Fig. 2 .

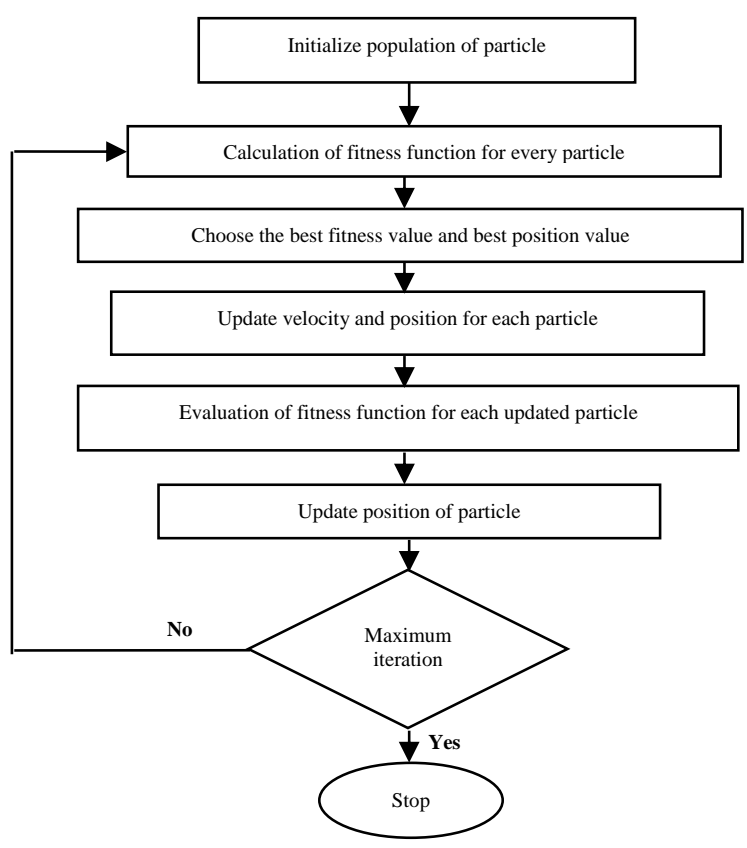

Fig. 2. Flow chart for particle swarm optimization

\section{Basic Steps in Particle Swarm Optimization}

1. Population is initialized with particle of random position and velocities.

2. The fitness function is calculated for every particle.

3. The current fitness value of the particle's is compared with other particle's fitness value and finds $\mathrm{P}_{-} \mathrm{b}$ value.

4. Compare the overall previous best value of population and fitness value to obtain $G$ _b.

5. By using the following (1) and (2) equation, particle's position and velocity will update.

6. If the number of equation is reached maximum, then stop otherwise repeat from step 2.

$$
\begin{gathered}
V_{t}^{i d}=V_{t}^{i d}+c_{1} r_{1}\left(P_{t}^{i d}-S_{t}^{i d}\right)+c_{2} r_{2}\left(P_{g d}^{i d}-S_{t}^{i d}\right) \\
S_{t}^{i d+1}=S_{t}^{i d}+V_{t}^{i d+1}
\end{gathered}
$$

where, the velocity for particle $\mathrm{t}$ is $V_{t}^{\text {id }}$ and position of the particle $\mathrm{t}$ is $S_{t}^{i d}$. Index of the particle is $t . r_{l}, r_{2}$ are arbitrary numbers, belongs to $(0,1)$ and $c_{1}, c_{2}$ are random 
variable. $P_{t}^{i d}$ is the best local position of $t^{\text {th }}$ particle and $P_{g d}{ }^{i d}$ is the global best position of $t^{\text {th }}$ particle [20].

\section{1) Application Areas for particle swarm optimization}

Particle Swarm Optimization application are really helpful in solving system control ,telecommunications, power systems, design, signal processing, network training, and many other areas. Nowadays PSO algorithms are developing to solve controlled problems, multi-purpose problems on optimization, it is also used to solve optimization problem in the areas of electric power systems.

\section{2) Advantages of particle swarm optimization in Task Scheduling}

PSO algorithm assign task to the virtual machine in the manner of best fit. Here task check's the virtual machine and task is assigned to the proper virtual machine that has minimum wastage of memory. Particle swarm optimization is used to scheduling applications in cloud resources that take transmission cost and computation cost into account.

\section{Ant Colony Optimization}

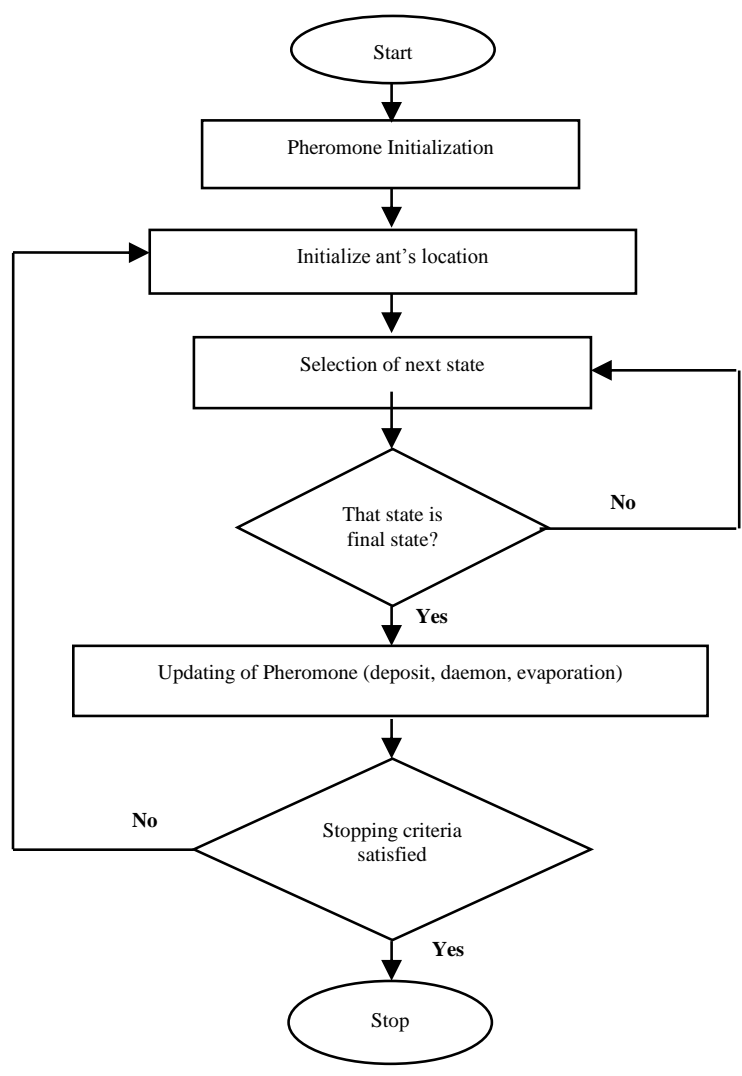

Fig. 3. Flow chart for ant colony optimization

Ants basically are simple being, they jointly forms a ant colony which do important tasks including shortest path traversal to find food source and information sharing with other ants by generating pheromone. In the field of ant colony optimization, models of collective intelligence of ants are transformed into useful optimization techniques that finding uses in computer networking[21].
In our survey, the problem-solving hypothesis of ACO is compared to traditional routing algorithms along with the issues of routing information, routing overhead and adaptively. With time, the evaporation of the pheromone trace starts. Which in turn thus reduces the attractive strength? The more time it takes for an ant to travel down the path and back again, the more time the pheromones have to evaporate. The shortest path is selected which, gets marched over more frequently, and thus the pheromone density becomes higher on shorter paths than longer ones. Basic steps of ACO are represented in Fig. 3.

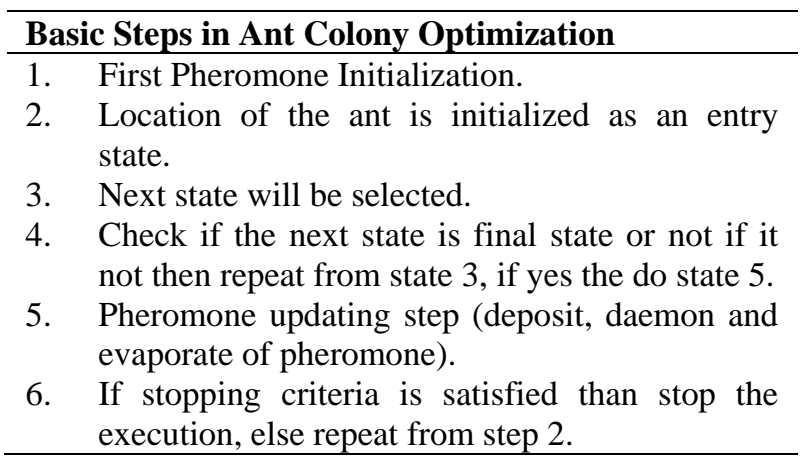

\section{1) Application Areas for ant colony optimization}

Ant colony optimization is based on ant's behavior and has been applied to discrete optimization problems. Ant colony optimization algorithms are useful for combinatorial optimization and stochastic problems, multi-target and parallel implementations.

\section{2) Advantages of ant colony optimization in Task Scheduling}

It has number of advantages with some critical issues that to be determined in order to enhance reliability of the cloud system. Such problems are associated with the fault acceptance, load balancing, and variety of security related issues in cloud computing system. The main concern of this paper is load balancing in cloud computing environment. The load can be memory capacity, CPU load, network load, delay in network, etc.

\section{Artificial Bee Colony}

The artificial bee colony algorithm relies on bees activities during searching for nectar and information sharing with other bees. Three types of agents are generally present the onlooker, employed, and the scout bees. The employed bee resides on the source of the food and gives its surroundings in memory; the onlooker takes this data from employed bees and selects the source of the food. The scouts are responsible for finding the nectar source.

The whole bee hive has been observed, so that some components can be differentiated. The main constituent of the hive regarding exchanging information and knowledge is the dancing region. Entire communication between bees relating locality and food quality sources occur in the dancing area. The dance of association is called waggle dance. As information about all good food sources is available to an onlooker bee which exists on 
the dance floor. Onlooker bee possibly could watch many dances and then she opts to make use of herself at the most beneficial source[22]. Following figure 4 describes the basic steps of bee colony optimization. Basic steps for artificial bee colony optimization is as follows.

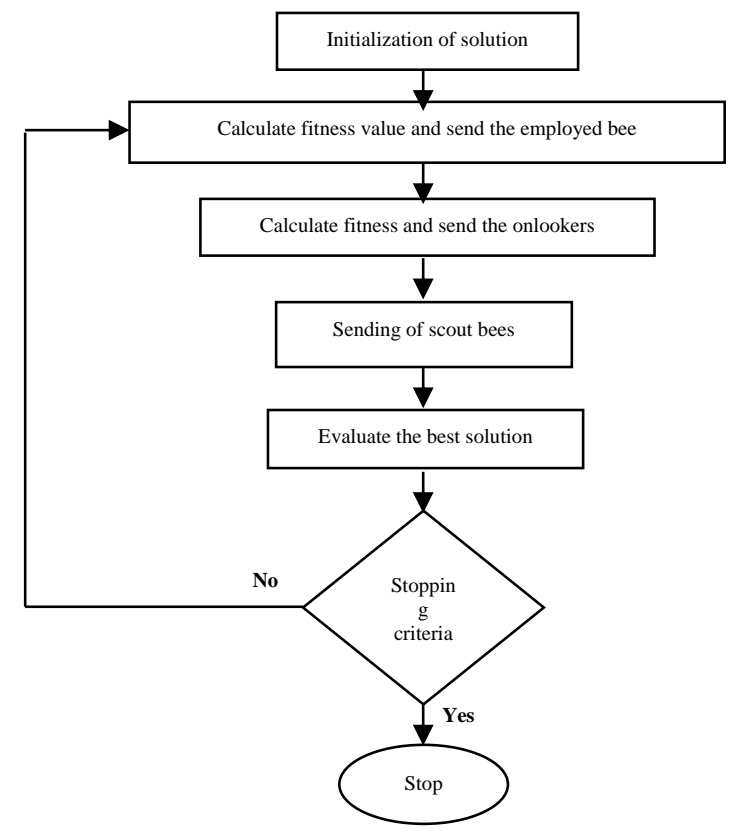

Fig. 4. Flow chart for artificial bee colony

\section{Basic Steps in Artificial Bee Colony}

1. Control parameter initialization.

2. Solution initialization.

3. Calculation of fitness value and employed bee sending.

4. Calculation of fitness value and the onlooker's bee sending.

5. Send the Scout bees.

6. Evaluate the best solution.

7. Stopping criteria checking if match then stop, otherwise repeat from 3

\section{1) Application Areas for artificial bee colony}

It provides a very good quality approach for structural optimization. It also provides a good explanation to MR brain image classification and inference of face pose.

\section{2) Advantages of artificial bee colony in Task Scheduling}

It is used for numerical optimization. It can be also used for combinatorial optimization problem. It can be used for unconstrained and constrained optimization problems. It employs only three control parameters (population size maximum cycle number and limit.

\section{VARIOUS TECHNIQUES IN TABULAR FORM}

Table 1. Techniques of various GA

\begin{tabular}{|c|c|c|c|c|}
\hline Algorithm & Authors & Key objective & Application areas & Issues \\
\hline $\begin{array}{lr}\text { GA } & \text { based } \\
\text { advanced } & \text { task } \\
\text { scheduling. } & \\
\end{array}$ & $\begin{array}{l}\text { Banerjee, Adhikari } \\
\text { and Biswas [7] } \\
(2012)\end{array}$ & $\begin{array}{l}\text { Optimized waiting } \\
\text { time of the system. }\end{array}$ & $\begin{array}{l}\text { Selection of best job sequence and } \\
\text { particular resources to optimize the } \\
\text { solution. }\end{array}$ & $\begin{array}{l}\text { Increase the system's QoS and } \\
\text { minimize the execution time. }\end{array}$ \\
\hline Improved GA. & $\begin{array}{l}\text { Kumar and Verma } \\
\text { [8] (2012) }\end{array}$ & $\begin{array}{l}\text { Utilization of } \\
\text { resources efficiently, } \\
\text { proper allocation of } \\
\text { requested resources. }\end{array}$ & $\begin{array}{l}\text { Properly utilizes resource by } \\
\text { combining three } \\
\text { algorithm } \\
\text { maximum-minimum, GA). }\end{array}$ & $\begin{array}{l}\text { Minimization of makespan and } \\
\text { execution cost. }\end{array}$ \\
\hline $\begin{array}{l}\text { GA based } \\
\text { scheduling } \begin{array}{r}\text { of } \\
\text { independent task. }\end{array}\end{array}$ & $\begin{array}{l}\text { Zhao, Zhang and } \\
\text { Liu [23] (2009) }\end{array}$ & $\begin{array}{l}\text { Divisibility of tasks } \\
\text { among heterogeneous } \\
\text { system. }\end{array}$ & $\begin{array}{l}\text { Find best fit solution by conflicting } \\
\text { measurement. }\end{array}$ & $\begin{array}{l}\text { Proper utilization of resources and } \\
\text { time for heterogeneous } \\
\text { computation. }\end{array}$ \\
\hline $\begin{array}{l}\text { GA based } \\
\text { dynamic } \\
\text { scheduling. }\end{array}$ & $\begin{array}{lr}\text { Ravichandran } & \text { and } \\
\text { Naganathan } & {[24]} \\
(2013) & \\
\end{array}$ & $\begin{array}{l}\text { Allocation } \quad \text { and } \\
\begin{array}{l}\text { appropriate use of } \\
\text { resources. }\end{array} \\
\end{array}$ & $\begin{array}{l}\text { Natural selection of tasks according } \\
\text { to the usage of memory. }\end{array}$ & $\begin{array}{l}\text { Globally optimized and reduce of } \\
\text { time by equivalent processing. }\end{array}$ \\
\hline
\end{tabular}

Table 2. Techniques of various PSO

\begin{tabular}{|c|c|c|c|c|}
\hline Algorithm & Authors & Key objective & Application areas & Issues \\
\hline $\begin{array}{l}\text { Assignment of task } \\
\text { based on PSO. }\end{array}$ & $\begin{array}{l}\text { Guo, Shao and Zhao [9] } \\
(2012)\end{array}$ & $\begin{array}{l}\text { Optimization of multi } \\
\text { objective (cost and time). }\end{array}$ & $\begin{array}{l}\text { Number of parameter is } \\
\text { less and scalability } \\
\text { enhances. }\end{array}$ & $\begin{array}{l}\text { Proficient and reduce the } \\
\text { time and cost. }\end{array}$ \\
\hline Heuristic based PSO. & $\begin{array}{l}\text { Pandey, Wu, Guru and } \\
\text { Buyya [10] (2010) }\end{array}$ & $\begin{array}{l}\text { Minimization of cost for } \\
\text { computation } \\
\text { communication. }\end{array}$ & $\begin{array}{l}\text { Changing the cost of } \\
\text { communication total cost } \\
\text { is calculated. }\end{array}$ & $\begin{array}{l}\text { Execution cost } \\
\text { minimization and } \\
\text { balances the workflow. }\end{array}$ \\
\hline Hybrid PSO. & Xue and Wu [11] (2010). & $\begin{array}{l}\text { Proper scheduling of } \\
\text { resources. }\end{array}$ & $\begin{array}{l}\text { Able for global searching, } \\
\text { in the early evolution } \\
\text { stage. }\end{array}$ & $\begin{array}{l}\text { Minimization of } \\
\text { execution time and cost, } \\
\text { develop the capacity of } \\
\text { local search. }\end{array}$ \\
\hline Revised discrete PSO. & $\begin{array}{l}\text { Wu, Ni, Gu and Liu [25] } \\
\text { (2010) }\end{array}$ & $\begin{array}{l}\text { Scheduled workflow } \\
\text { application and cost } \\
\text { minimization. }\end{array}$ & $\begin{array}{l}\text { Comparing and } \\
\text { Considering the ratio of } \\
\text { cost optimization cost } \\
\text { saving is done. }\end{array}$ & $\begin{array}{l}\text { Better optimized cost and } \\
\text { makespan } \\
\text { performance. }\end{array}$ \\
\hline
\end{tabular}


Table 3. Techniques of various ACO

\begin{tabular}{|l|l|l|l|l|}
\hline Algorithm & Authors & Key objective & Application areas \\
\hline $\begin{array}{l}\text { Load balancing based } \\
\text { ACO. }\end{array}$ & $\begin{array}{l}\mathrm{Li}, \mathrm{Xu}, \text { Zhao and Dong } \\
{[26](2011) .}\end{array}$ & $\begin{array}{l}\text { Balancing load of the } \\
\text { system and schedule tasks. }\end{array}$ & $\begin{array}{l}\text { Improve the ability of } \\
\text { balancing } \\
\text { virtual machine. }\end{array}$ & $\begin{array}{l}\text { System load balancing } \\
\text { dynamically adopted. }\end{array}$ \\
\hline ACO & $\begin{array}{l}\text { Chiang, Lee, Lee and } \\
\text { Chou [12] (2006). }\end{array}$ & $\begin{array}{l}\text { Optimize the time of task } \\
\text { completion. }\end{array}$ & $\begin{array}{l}\text { Integration of local search Improve the efficiency and } \\
\text { and Taguchi Method use } \\
\text { to improve efficiency. }\end{array}$ & $\begin{array}{l}\text { Ime } \\
\text { time } \\
\text { heterogeneous system. }\end{array}$ \\
\hline
\end{tabular}

Table 4. Techniques of various BCO

\begin{tabular}{|l|l|l|l|l|}
\hline Algorithm & Authors & Key objective & Application areas \\
\hline $\begin{array}{l}\text { Load balancing based } \\
\text { on honey bee } \\
\text { behavior. }\end{array}$ & $\begin{array}{l}\text { Babu and Venkata Krishna } \\
{[15](2013)}\end{array}$ & $\begin{array}{l}\text { Maximization } \\
\text { throughput. }\end{array}$ & $\begin{array}{l}\text { Prioritization of tasks and } \\
\text { distributes the load among } \\
\text { VMs. }\end{array}$ & $\begin{array}{l}\text { Optimized utilization of } \\
\text { machines, minimum time } \\
\text { to wait. }\end{array}$ \\
\hline Binary-ABC. & $\begin{array}{l}\text { Kim, Liu and McLoone } \\
{[16](2013)}\end{array}$ & Optimized solution. & $\begin{array}{l}\text { Use of few parameter for } \\
\text { control and spread } \\
\text { searching. }\end{array}$ & $\begin{array}{l}\text { Reduces the makespan, } \\
\text { better performance. }\end{array}$ \\
\hline
\end{tabular}

\section{CONCLUSION}

Since cloud computing has the potential to effectively serve future computing needs, it is compulsory to optimally manage the major issues arising due to excess computation in clouds. Task scheduling is one of the important factors that affect the resource utilization and cloud performance. A large quantity of research work is available to efficiently schedule tasks with available resources. This paper has surveyed some best swarm based scheduling techniques from the domain of soft computing with their advantages and application areas. Future work will cover some more issues related to task scheduling and advanced scheduling heuristics.

\section{REFERENCES}

[1] Alex Comninos, "Emerging issues: cloud computing", Southern African Internet Governance Forum, Issue Papers No. 1 of 5, 2011, pp.1-7.

[2] Muhammad Baqer Mollah, Kazi Reazul Islam and Sikder Sunbeam Islam, "Next generation of computing through cloud computing technology", 25th IEEE Canadian Conference on Electrical and Computer Engineering, 2012, pp. 1-6.

[3] Yashpalsinh Jadeja and Kirit Modi, "Cloud computing concepts, architecture and challenges", International Conference on Computing, Electronics and Electrical Technologies, 2012, pp.877-880.

[4] L. Guo, S. Zhao, S. Shen and C. Jiang, C, "Task Scheduling Optimization in Cloud Computing Based on Heuristic Algorithm", Journal Of Networks, Vol. 7, No. 3, March 2012, 547-553.

[5] CT Lin, "Comparative Based Analysis of Scheduling Algorithms for Resource Management in Cloud Computing Environment", JCSE International Journal of Computer Science and Engineering, Vol.1, No.1, 2013, 17-23.

[6] Savitha. P and J Geetha Reddy," A Review Work on Task Scheduling in Cloud Computing Using Genetic Algorithm", International Journal of Scientific \& Technology Research, Vol. 2, Issue 8, 2013, pp.241-244.

[7] Sourav Banerjee, Mainak Adhikari and Utpal Biswas, "Advanced Task Scheduling for Cloud Service Provider Using Genetic Algorithm", IOSR Journal of Engineering, Vol. 2, No. 7, 2012, pp. 141-147.
[8] Pardeep Kumar and Amandeep Verma, "Scheduling Using Improved Genetic Algorithm in Cloud Computing for Independent Tasks", International Conference on Advances in Computing, Communications and Informatics, 2012, pp.137-142.

[9] Lizheng Guo and Guojin Shao, "Multi-objective Task Assignment in Cloud Computing by Particle Swarm Optimization", 8th International conference on Wireless Communications, Networking and Mobile Computing (WiCOM), 2012, pp.1-4.

[10] Suraj Pandey, LinlinWu, Siddeswara Mayura Guru and Rajkumar Buyya, "A Particle Swarm Optimization-based Heuristic for Scheduling Workflow Applications in Cloud Computing Environments", IEEE International Conference on Advanced Information Networking and Applications, 2010, pp. 400 - 407.

[11] Sheng-Jun Xue and Wu, "Scheduling Workflow in Cloud Computing Based on Hybrid Particle Swarm Algorithm", TELKOMNIKA, Vol.10, No.7, 2012, pp. 1560-1566.

[12] C.W. Chiang, Y.C. Lee, C.N. Lee and T.Y Chou, "Ant colony optimisation for task matching and scheduling", IEEE Proc.-Computer Digital. Techniques, Vol. 153, No. 6, 2006, pp.373-379.

[13] Linan Zhu, Qingshui Li and Lingna He, "Study on Cloud Computing Resource Scheduling Strategy Based on the Ant Colony Optimization Algorithm", IJCSI International Journal of Computer Science Issues, Vol. 9, No. 2, 2012, pp.54-58.

[14] Hui Liu, Dong Xu and HuaiKou Miao, "Ant Colony Optimization Based Service flow Scheduling with Various QoS Requirements in Cloud Computing", First ACIS International Symposium on Software and Network Engineering, 2011 , pp.53-57.

[15] Dhinesh Babu L.D. and P. Venkata Krishna, "Honey bee behaviour inspired load balancing of tasks in cloud computing environments", Applied Soft Computing, Vol. 13, No. 5, 2013, pp. 2292-2303.

[16] Sung-Soo Kim, Ji-Hwan Byeon, Hongbo Liu, Ajith Abraham and Seán McLoone, "Optimal job scheduling in grid computing using efficient binary artificial bee colony optimization", Soft Computing, Vol. 17, No. 5, 2013, pp 867-882.

[17] Saurabh Bilgaiyan, Santwana Sagnika and Madhabananda Das, "Workflow Scheduling in Cloud Computing Environment Using Cat Swarm Optimization", International Journal of Computer Applications, Vol .89, No.2, 2014, pp. 680 - 685.

[18] Andrew J. Page and Thomas J. Naughton, "Dynamic task scheduling using genetic algorithms for heterogeneous 
distributed computing", 19th IEEE International Conference on Parallel and Distributed Processing Symposium, 2005, pp. 189a.

[19] J. H. Holland. Adaptation in Natural and Artificial Systems.MIT Press, Cambridge, MA, USA, 1992.

[20] W. Qing, and Z. Han-Chao, "Optimization of Task Allocation And Knowledge Workers Scheduling Basedon Particle Swarm Optimization, "In Proceedings of IEEE International Conference on Electric Information and Control Engineering, 2011, pp. 574-578.

[21] Liang Bai, Yan-Li Hu, Song-Yang Lao, Wei-Ming Zhang, "Task scheduling with load balancing using multiple ant colonies optimization in grid computing", IEEE Sixth International Conference on NaturalComputation (ICNC 2010), 2010, pp.2715-2719.

[22] Salim Bitam, "Bees Life Algorithm for Job Scheduling in Cloud Computing", Proceedings of The Third International Conference on Communications and Information Technology, 2012, pp. 186-191.

[23] Chenhong Zhao, Shanshan Zhang and Qingfeng Liu, "Independent Tasks Scheduling Based on Genetic Algorithm in Cloud Computing ", 5th IEEE International Conference on Wireless Communications, Networking and Mobile Computing, 2009, pp. 1-4.

[24] S. Ravichandran and Dr. E.R. Naganathan, "Dynamic Scheduling of Data Using Genetic Algorithm in Cloud Computing", International Journal of Computing Algorithm, Vol. 02, Issue 01, 2013, pp. 127-133.

[25] Zhangjun $\mathrm{Wu}$, Zhiwei Ni, Lichuan Gu and Xiao Liu , "A Revised Discrete Particle Swarm Optimization for Cloud Workflow Scheduling", IEEE International Conference Computational Intelligence and Security (CIS), 2010, pp.184-188.

[26] Kun Li, Gaochao Xu, Guangyu Zhao, Yushuang Dong and D. Wang, "Cloud Task Scheduling Based on Load Balancing Ant Colony Optimization", Sixth Annual IEEE Chinagrid Conference (ChinaGrid), 2011, pp. 3-9.

\section{Authors' Profiles}

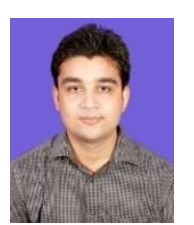

Saurabh Bilgaiyan is pursuing Ph.D. (CSE) at KIIT University, Bhubaneswar, India. He obtained Bachelor's degree as B.E. (I.T.) in 2012 from B.I.R.T., Bhopal, India and Master's degree as M.Tech. (CSE) in 2014 from KIIT University, Bhubaneswar, India. His area of interest includes soft computing, cloud computing, image processing, distributed database systems, software cost estimation.

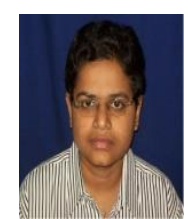

Santwana Sagnika is currently working as an Assistant Professor in KIIT University, Bhubaneswar, India. She is also pursuing Ph.D. (CSE) at KIIT University, Bhubaneswar. She obtained her Bachelor's degree as B.Tech (CSE) in 2011 and masters as M.Tech (CSE) in 2014 from KIIT university, Bhubaneswar, India. Her area of interest includes soft computing, image processing and cloud computing.

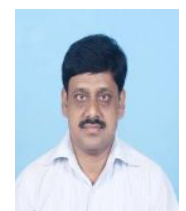

Samaresh Mishra, M.Tech, Ph.D. (Computer Science) is the Dean of School Computer Engineering, KIIT University, India. He has rich experience of teaching in the field of Computer Science at both UG and PG degree level as well as published many articles in International Conference and Journals of repute. His area of interest includes Database Engineering, Cost Estimation, Software Reliability, Cloud Computing.

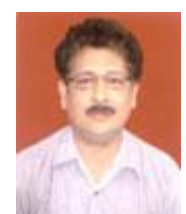

Madhabananda Das, M.Tech., Ph.D. is Senior Professor of School Computer Engineering, KIIT University, India. He has rich experience of teaching in the field of Computer Science at both UG and PG degree level as well as published many articles in International Conference and Journals of repute. His area of interest includes soft computing and computational intelligence, image processing. 